\title{
Consumers' attitudes about milk quality and fertilization methods in dairy cows in Germany
}

\author{
Laura Pieper, ${ }^{*}$ M. G. Doherr, ${ }^{*}$ and W. Heuwieser ${ }^{1}$ \\ *Institute for Veterinary Epidemiology and Biostatistics, and \\ †Clinic of Animal Reproduction, Free University of Berlin, 14163 Berlin, Germany
}

\begin{abstract}
Major advances in assisted reproductive technologies have improved reproductive efficiency in dairy cattle. However, these developments occurred regardless of the perception of consumers, who often distrust biotechnology in food production. Therefore, the objective of this study was to investigate consumers' attitudes toward reproductive management practices in dairy cattle. In November 2012, 1,646 participants were interviewed by a commercial market research institute. Participants were selected from all regions and demographic categories to represent the general public in Germany. Seven questions regarding milk-drinking preferences and reproductive technologies were asked in face-toface interviews. Descriptive statistics and multivariable logistic regression models were used. The majority of people drank milk at least weekly $(63 \%)$ and found the taste of milk important (60\%). Most people perceived advanced reproductive technologies negatively [e.g., the use of sexed semen $(53 \%)$, embryo transfer $(58 \%)$, cloning $(81 \%)$, and hormone treatments to increase fertility (65\%)]. Many people lacked basic knowledge about milk production (22\% did not know that cows only give milk after calving; $51 \%$ did not know that milk naturally contains hormones); however, participants with a high school education, older participants, and those who had concerned themselves with dairy farming were more knowledgeable. Education and providing information might help to inform the public about reproductive management practices in dairy cows.
\end{abstract}

Key words: consumer attitude, consumer knowledge, reproductive technology, milk quality

\section{INTRODUCTION}

A wide variety of methods, tools, and management practices have been developed to ensure or improve

Received July 24, 2015.

Accepted December 17, 2015.

${ }^{1}$ Corresponding author: w.heuwieser@fu-berlin.de fertility of individual dairy cows and reproductive performance of animal populations in the past century. The development of assisted reproductive technologies in dairy cattle has been extensively reviewed (Foote, 2002; Moore and Thatcher, 2006). These methods include AI, endocrinological approaches (e.g., hormone therapy, synchronization protocols), embryo transfer, in vitro embryo production, use of sexed semen, cloning, and preimplantation diagnostic screening techniques. Their developments have been driven by different objectives, such as controlling venereal diseases (Foote, 2002), increasing genetic merit (Moore and Thatcher, 2006), increasing labor efficiency (Tenhagen et al., 2004), or facilitating insemination of cows at a predictable time relative to ovulation without estrus detection (e.g., Pursley et al., 1995; Rabiee et al.,2005). These technologies led to enormous increases in milk production but were accompanied by a decline in reproductive efficiency in high-producing cows worldwide (e.g., Lucy, 2001). Although high milk production and good reproductive performance are not mutually exclusive, this decline in fertility has likely perpetuated more research and development of new reproductive technologies that are widely applied in the dairy industry (von Keyserlingk et al., 2013).

Today, hormonal synchronization protocols have been widely adopted (Fricke et al., 2014) and the dairy industry relies heavily on the use of exogenous hormones to mitigate challenges associated with low fertility (Moore and Thatcher, 2006). Timed AI protocols to manage reproductive performance of at least some of the heifers or cows were used by $58 \%$ of all US dairy farms in 2007 (USDA, 2009). Although negative pharmacological effects on animal or human health have not yet been described, it has been speculated that few consumers are aware of such reproductive management practices (von Keyserlingk et al., 2013), and that consumers would likely perceive this type of assisted reproductive techniques to be unnatural and unwelcome (Boogaard et al., 2011).

Public perception of milk products arising from the introduction of new technologies is difficult to assess 
(von Keyserlingk et al., 2013). In general, the public frequently distrusts the use of biotechnology in food production (Gaskell et al., 2000; Lassen et al., 2006). More specifically, the public perceives hormones undesirably as the word "hormones" holds negative connotations in the context of food production (Higgins et al., 2013; Jung et al., 2015). The potential impact of consumer perceptions regarding these techniques and hormone use in reproductive management programs should not be underestimated and will likely play a significant role in determining future management practices (von Keyserlingk and Heuwieser, 2008). A negative consumer attitude could eventually result in image problems for the dairy industry. In addition to hormone use, there is a lack of information on how the public perceives practices or reproductive methods applied in the dairy industry today.

Consumers' attitudes about food might be associated with their knowledge about the industry (Hallman et al., 2003). Factors influencing knowledge and attitudes about food might include age (Verbeke and Viaene, 1999; Hallman et al., 2003; Worsley et al., 2013), sex (Rozin et al., 1999; Verbeke and Viaene, 1999; Hallman et al., 2003), education (Hallman et al., 2003; Worsley et al., 2013), place of residence (urban or rural; Weatherell et al., 2003), and whether or not the consumer has children (Schröck, 2014). Furthermore, whether or not the consumer knows a producer personally might also influence the attitude (Institute for Demoscopy Allensbach, 2002). Due to the different structures of the dairy industry in southern, western, and eastern Germany, with fewer, larger farms in eastern Germany and more numerous, smaller farms in southern and western Germany (Statistisches Bundesamt, 2013), one might speculate that consumers in eastern Germany less often know a farmer personally (Institute for Demoscopy Allensbach, 2002) and, therefore, have a more negative attitude toward the dairy industry.

Therefore, the objective of this study was to benchmark consumers in Germany regarding their attitudes about certain reproductive management practices in dairy cattle. Specifically, we set out to (1) evaluate consumers' knowledge and perceptions about reproductive methods in modern dairy farming, and (2) determine potential associations between consumers' demographic characteristics and knowledge about dairy farming.

\section{MATERIALS AND METHODS}

\section{Questionnaire}

Between November 10 and November 22, 2012, a commercial market research institute (Institute for De- moscopy Allensbach, Allensbach, Germany) conducted a survey on behalf of the Clinic of Animal Reproduction, Freie Universität Berlin (Berlin, Germany). Participants were selected from all regions in Germany and had to be 16 yr of age or older. Participants were recruited personally (friends or relatives) by 467 interviewers and were selected based on quotas to represent proportions similar to census distributions (Statistisches Bundesamt, 2011) in terms of demographic data; that is, region, state, size of residence, sex, age, occupation, type of occupation, marital status, and size of household. The interviews were usually conducted in the participants' homes and no incentive was provided for participation. The interviewers themselves were also selected to represent the desired regional distribution.

The questions for this study $(\mathrm{n}=7)$ were part of a multi-topic questionnaire (Hauptbefragung 11001 November/December 2012) containing 70 questions. The time required to complete the questionnaire in a faceto-face interview was about $50 \mathrm{~min}$. The time required to complete the 7 questions related to this study was not separately recorded. Before the study questions, the topics of insurance companies and driving habits were investigated for other purposes. The questions were developed by questionnaire specialists from the Allensbach Institute and were pretested for comprehension and technical functionality. The interviewers were instructed to read the questions aloud and always ask the questions in the same order. Technical help was provided to the interviewee if necessary (Appendix Table A1).

\section{Statistical Analysis}

Frequency distributions over all categorical variables were calculated to describe the data. Sampling was disproportionally higher in eastern states by approximately one-third more than would be representative for the proportion of inhabitants (19\%). This disproportionality was accounted for using weighted analysis. States were categorized into the following regions: south (Bavaria and Baden-Württemberg), west (North Rhine-Westphalia, Rhineland-Palatinate, Saarland, Hesse, Bremen, Hamburg, Lower Saxony, and Schleswig-Holstein), and east (Berlin, Brandenburg, Saxony, Saxony-Anhalt, Thuringia, and MecklenburgWestern Pomerania). Multivariable logistic regression models were built for 2 questions: (a) "A cow can only give milk when she already gave birth to a calf. Have you heard about that or have you not heard about that but you would have expected it or you would have not necessarily thought that?" and (b) "The milk that comes from healthy cows that did not receive 
hormone treatment also contains hormones. Did you know that or did you not know that?" as outcomes. Age, sex, education, region, place of residence (city or countryside), frequency of milk consumption, whether or not the participants had children, and whether or not the participants had concerned themselves with dairy production were tested as the predictors in both models. Region was tested in the models to investigate whether different structures of dairy farming (larger dairy farms in the east and smaller farms in the west and south) influenced knowledge and attitudes. For the first model, answer categories "I have heard that" and "I would have thought that" were combined into one category ("Participant knew that cows only give milk after calving"). Chi-square tests were conducted to screen for individual associations between all predictors and the 2 outcome variables, and those with $P<0.1$ were tested in the respective multivariable model. Only plausible interactions among predictors were tested for significance in the models. Manual forward selection was used to build the models, and final models were assessed using Hosmer-Lemeshow test and residual analysis. For building the regression models, observations with the answer category "No answer" in predictors or outcomes were excluded from the analysis. Statistical analyses were performed using the computer program
SPSS (version 22, IBM Corp., Armonk, NY). A P-value $<0.05$ was considered significant.

\section{RESULTS}

In total, 1,646 participants consented to be interviewed. Demographic characteristics were similar in participants and the general German population (Table 1). Over $50 \%$ of participants drank milk either multiple times per week, daily, or multiple times per day (Table 2). About 60 and $49 \%$ found the taste of milk and the fat content important, respectively. The origin of the milk (small farm) and type (organic product) were important to some respondents only ( 8 and $12 \%$, respectively). More than $75 \%$ of participants had heard or would have thought that cows have to calve before producing milk. In total, $42 \%$ of all participants had concerned themselves with dairy farming. About $51 \%$ of participants thought that fertilization method would not influence milk quality. However, $18 \%$ believed that fertilization method would influence milk quality. Of those, most participants thought that AI with or without hormone treatment and embryo transfer would decrease milk quality. The majority of all participants disapproved of AI with sexed semen (53\%), embryo transfer $(58 \%)$, cloning $(80 \%)$, and hormone treatment

Table 1. Demographic information of 1,646 survey participants compared with official demographical data of the German population (Statistisches Bundesamt, 2011, Federal Statistical Office, Germany)

\begin{tabular}{|c|c|c|c|}
\hline \multirow[b]{2}{*}{ Item } & \multicolumn{2}{|c|}{ Survey participants } & \multirow{2}{*}{$\begin{array}{c}\text { Statistisches } \\
\text { Bundesamt }(\%\end{array}$} \\
\hline & Weighted no. & $\%$ & \\
\hline \multicolumn{4}{|l|}{ Regional distribution } \\
\hline Western states including western part of Berlin & 1,335 & 81 & 81 \\
\hline Eastern states including eastern part of Berlin & 312 & 19 & 19 \\
\hline \multicolumn{4}{|l|}{ Size of residence } \\
\hline Less than 5.000 inhabitants & 259 & 16 & 16 \\
\hline 5,000 to less than 20,000 inhabitants & 440 & 27 & 27 \\
\hline 20,000 to less than 100,000 inhabitants & 454 & 27 & 27 \\
\hline 100,000 and more inhabitants & 492 & 30 & 30 \\
\hline \multicolumn{4}{|l|}{ Sex } \\
\hline Men & 800 & 49 & 49 \\
\hline Women & 846 & 51 & 51 \\
\hline \multicolumn{4}{|l|}{ Age } \\
\hline $16-29 \mathrm{yr}$ & 305 & 19 & 19 \\
\hline $30-44 \mathrm{vr}$ & 364 & 22 & 22 \\
\hline $45-59$ yr & 446 & 27 & 27 \\
\hline $60 \mathrm{yr}$ and older & 530 & 32 & 32 \\
\hline \multicolumn{4}{|l|}{ Marital status } \\
\hline Married & 875 & 53 & 53 \\
\hline Single & 504 & 31 & 31 \\
\hline Widowed, divorced & 267 & 16 & 16 \\
\hline \multicolumn{4}{|l|}{ Size of household ( $16 \mathrm{yr}$ or older) } \\
\hline 1 person & 385 & 23 & 23 \\
\hline 2 persons & 653 & 40 & 40 \\
\hline 3 persons & 288 & 18 & 18 \\
\hline 4 persons & 232 & 14 & 14 \\
\hline 5 or more persons & 89 & 5 & 5 \\
\hline
\end{tabular}


to increase fertility (65\%). However, most people (51\%) did not know that milk naturally contains hormones without prior hormone administration.

Participants who had already concerned themselves with dairy farming were 4 times more likely (odds ratio $=4.2, P<0.001)$ to have thought that cows only give milk after calving (Table 3). Additionally, high school or university graduates and older participants answered more often that they would have thought that cows produce milk only after calving. Not included in the model were sex, region, place of residence, frequency of milk consumption, and whether or not the participants had children. The model fit the data well (HosmerLemeshow test, $P=0.943)$ and outliers were not detected.

Similarly, participants who graduated from high school or university (odds ratio $=1.8 ; P<0.001$ ) and older participants were more likely to know that milk from cows without hormone treatment also contains hormones (Table 4). We detected a significant interaction between frequency of milk consumption and whether or not consumers had concerned themselves with dairy farming (Figure 1). Consumers who had not concerned themselves with dairy farming were more likely to know that milk contains hormones without prior hormone treatment if they drank milk at least weekly compared with participants who drank milk less frequently. Consumers who had already concerned themselves with dairy farming were generally more likely to know that milk naturally contains hormones; however, there was no difference in the probability if they also drank milk more frequently. Not included in the model were sex, place of residence, and whether or not the participants had children. The Hosmer-Lemeshow test was not significant $(P=0.378)$ and outliers were not detected.

\section{DISCUSSION}

Although a variety of reproductive management practices such as AI and exogenous hormone use are being widely implemented in the dairy industry worldwide (e.g., Fricke et al., 2014) and improved applications of these methods are intensively researched, consumers' knowledge of such technologies and their potential impact on the perceptions of dairy products is more or less unknown (von Keyserlingk and Heuwieser, 2008).

To our knowledge, this is the first study describing results from a survey of consumer perception about reproductive management practices in dairy cows. By design, the distribution of participants among different demographic categories in this study was similar to that of the German population. A consumer study using a mail survey sent out to randomly selected California households (rather than based on quota) yielded a biased study population in terms of age, education, and ethnic group (Bruhn et al., 1992). Furthermore, the present study enrolled a large number of participants $(\mathrm{n}=1,646)$ and used one-on-one interviews rather than an online survey, which further increased validity of the results. Online surveys with self-enrollment might have had a biased group of participants in terms of age, sex, socioeconomic status, and education (Stopponi et al., 2009). However, as interviewers of the current study enrolled participants from their families and friends rather than a simple random sample from the population, we cannot be sure that the results are free of any bias. Nevertheless, the demographic distribution of participants was almost identical to that of the German population and, therefore, the results of this study can be considered representative of the public in Germany.

The questionnaire first contained questions about milk quality followed by questions on biotechnology in dairy cows. A positive attitude toward milk and milk quality might have influenced participants to think more positively about biotechnology. Future studies might consider asking the questions in a random rather than a specific order to avoid potential order effects. Despite the fact that the questions were generated by trained and professional personnel, some of the questions might have been formulated in a way that suggested a desired answer rather than leaving the desired answer category open. This might have biased the results toward a more positive attitude and more knowledge about the dairy industry.

It is surprising that organic products were important for $12 \%$ of participants. This is in contrast to the fact that only $2.9 \%$ of revenues from milk sales came from organic products in Germany in 2012 (Schaack et al., 2014). This difference might be explained by a high percentage of customers purchasing organic milk only occasionally rather than regularly (Schröck, 2014).

Approximately half of the participants (51\%) thought that fertilization method would not influence milk quality. The remaining participants either had no opinion or thought there was an effect on milk quality. Advanced reproductive technologies such as use of sexed semen, embryo transfer, cloning, or hormone treatment to increase fertility were perceived negatively by the majority of participants. Therefore, advanced reproductive technologies might not be in agreement with consumer preferences. This finding is similar to other researchers, who have reported consumers' concerns about the use of hormones in dairy production (Refsdal, 2000; Jung et al., 2015). Consumers can affect use and future development of reproductive technologies by refusing to buy certain products that were produced in ways they do not approve of (von Keyserlingk et al., 2013). Con- 
Table 2. Summary of responses by survey participants $(\mathrm{n}=1,646)$ to questions related to consumers' attitudes about milk quality and fertilization methods in dairy cows

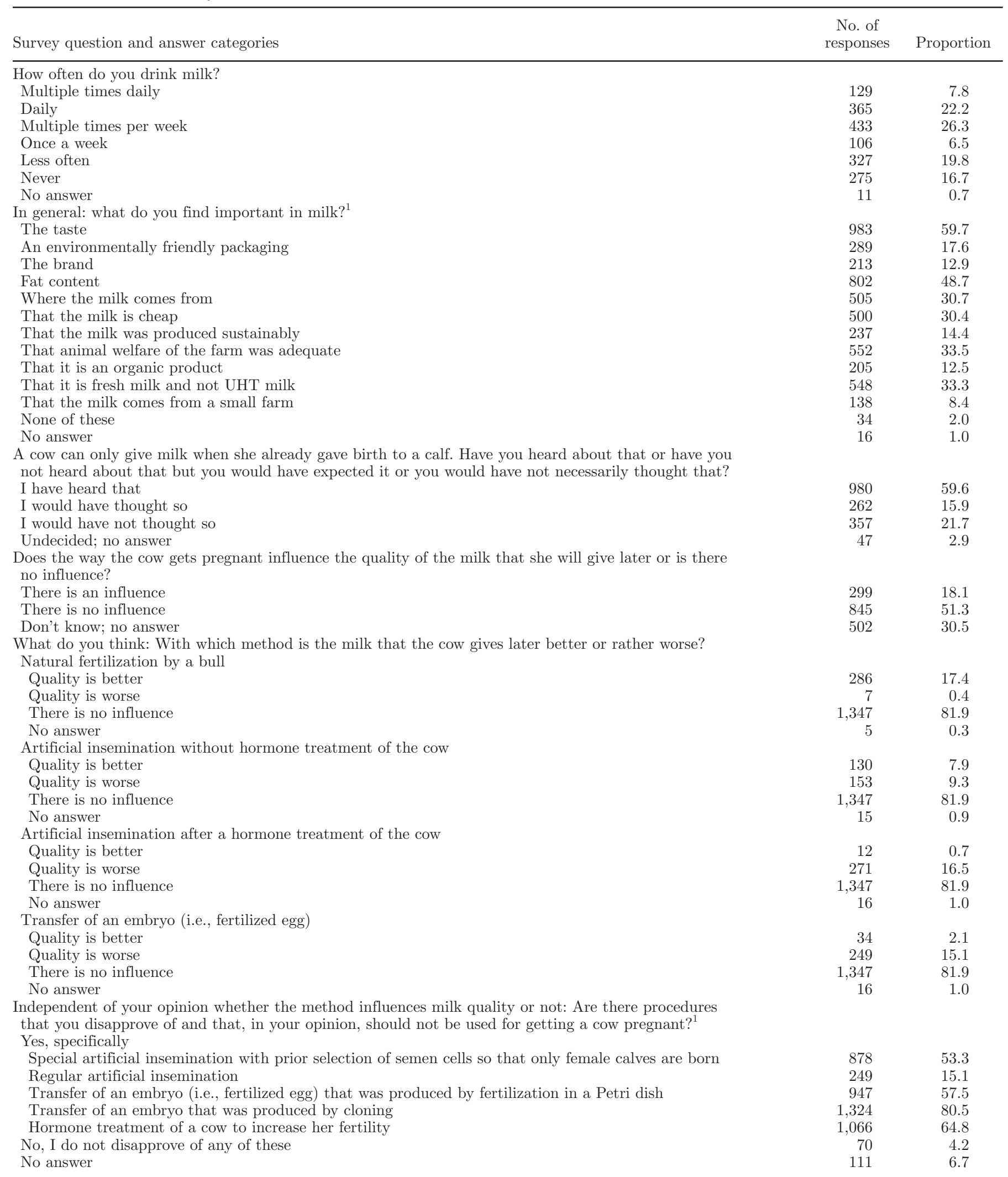


Table 2 (Continued). Summary of responses by survey participants $(\mathrm{n}=1,646)$ to questions related to consumers' attitudes about milk quality and fertilization methods in dairy cows

\begin{tabular}{|c|c|c|}
\hline Survey question and answer categories & $\begin{array}{l}\text { No. of } \\
\text { responses }\end{array}$ & Proportion \\
\hline \multicolumn{3}{|c|}{$\begin{array}{l}\text { The milk that comes from healthy cows that did not receive hormone treatment also contains } \\
\text { hormones. Did you know that or did you not know that? }\end{array}$} \\
\hline I knew that & 740 & 44.9 \\
\hline I did not know that & 837 & 50.8 \\
\hline No answer & 69 & 4.2 \\
\hline \multicolumn{3}{|c|}{$\begin{array}{l}\text { Have you ever concerned yourself with dairy farming; e.g., how dairy cows are housed, how milk is } \\
\text { produced, and so on, or is this not the case? }\end{array}$} \\
\hline Not the case & 922 & 56.0 \\
\hline No answer & 38 & 2.3 \\
\hline
\end{tabular}

${ }^{1}$ Multiple answers possible.

cerned citizens who oppose certain practices might also choose to give their political support to new regulations (von Keyserlingk et al., 2013).

In general, knowledge about basic reproductive biology of dairy cows was lacking in many participants. For example, $51 \%$ of consumers did not know that milk naturally contains hormones without prior hormone treatment. Consumers might be confused by getting to know that hormones are found in the milk and that hormones can be applied to dairy cows. They could be misled by thinking that these 2 facts were associated. However, both models showed that people who had concerned themselves with dairy farming were more knowledgeable compared with people who had not done so. This indicates that educational programs are needed to inform the public about the biology of dairy cows and dairy production practices (Curtis, 1987; Refsdal, 2000).

Participants who consumed milk frequently also more often knew about natural hormones in milk compared with participants who did not drink milk frequently. This finding, however, was only true for participants who had not concerned themselves with dairy produc- tion. This might indicate that people are more interested in milk production if they also drink milk frequently.

Older participants more often had better knowledge about dairy production than younger participants. This was expected because older participants have more life experience and potentially more exposure to dairyrelated topics in life. Participants with a high school education also had more knowledge about the biology of the dairy cow. This indicates that school education might help in informing the public about basic principles of food production. Similarly, Worsley et al. (2013) reported better knowledge about food safety in older and better-educated people. It might be that people with higher educational status are more interested in food production and quality per se and, therefore, inform themselves more often about food production practices.

Results from this study might motivate producers, veterinarians, and researchers to evaluate reproductive management practices in dairy cows. It might further stimulate dairy industry to better educate consumers about modern agricultural production. Although the strength of this study is its representative nature, the

Table 3. Multivariable logistic regression model predicting the probability of a participant knowing that cows only give milk after calving $(\mathrm{n}=1,569)$

\begin{tabular}{|c|c|c|c|c|}
\hline \multirow[b]{2}{*}{ Item } & \multirow[b]{2}{*}{ Odds ratio } & \multicolumn{2}{|c|}{$95 \% \mathrm{CI}$} & \multirow[b]{2}{*}{ Wald $P$-value } \\
\hline & & Lower limit & Upper limit & \\
\hline \multicolumn{5}{|l|}{ School education } \\
\hline Junior high or elementary school & Baseline & - & - & - \\
\hline High school or university graduate & 1.6 & 1.20 & 2.14 & 0.001 \\
\hline \multicolumn{5}{|l|}{ Concerned oneself with dairy farming } \\
\hline No & Baseline & - & - & - \\
\hline Yes & 4.2 & 3.11 & 5.61 & $<0.001$ \\
\hline \multicolumn{5}{|l|}{ Age category } \\
\hline $16-29 \mathrm{yr}$ & Baseline & - & - & - \\
\hline $30-44$ yr & 1.7 & 1.16 & 2.40 & 0.006 \\
\hline $45-59$ yr & 2.1 & 1.49 & 3.06 & $<0.001$ \\
\hline $60 \mathrm{yr}$ or older & 2.7 & 1.89 & 3.89 & $<0.001$ \\
\hline
\end{tabular}


Table 4. Multivariable logistic regression model predicting the probability that a participant knew that milk contains hormones without prior hormone treatment $(\mathrm{n}=1,547)$

\begin{tabular}{|c|c|c|c|c|}
\hline \multirow[b]{2}{*}{ Item } & \multirow[b]{2}{*}{ Odds ratio } & \multicolumn{2}{|c|}{$95 \% \mathrm{CI}$} & \multirow[b]{2}{*}{ Wald $P$-value } \\
\hline & & Lower limit & Upper limit & \\
\hline \multicolumn{5}{|l|}{ School education } \\
\hline Junior high or elementary school & Baseline & - & - & - \\
\hline High school or university graduate & 1.8 & 1.42 & 2.28 & $<0.001$ \\
\hline \multicolumn{5}{|l|}{ Age category } \\
\hline $16-29 \mathrm{yr}$ & Baseline & - & - & - \\
\hline 60 yr or older & 1.7 & 1.21 & 2.33 & 0.002 \\
\hline \multicolumn{5}{|l|}{ Concerned oneself with dairy farming } \\
\hline No & Baseline & - & - & - \\
\hline Yes & 4.5 & 3.13 & 6.61 & $<0.001$ \\
\hline \multicolumn{5}{|l|}{ Frequency of milk consumption } \\
\hline Less than weekly & Baseline & - & - & - \\
\hline Weekly or more often & 1.6 & 1.22 & 2.23 & 0.001 \\
\hline
\end{tabular}

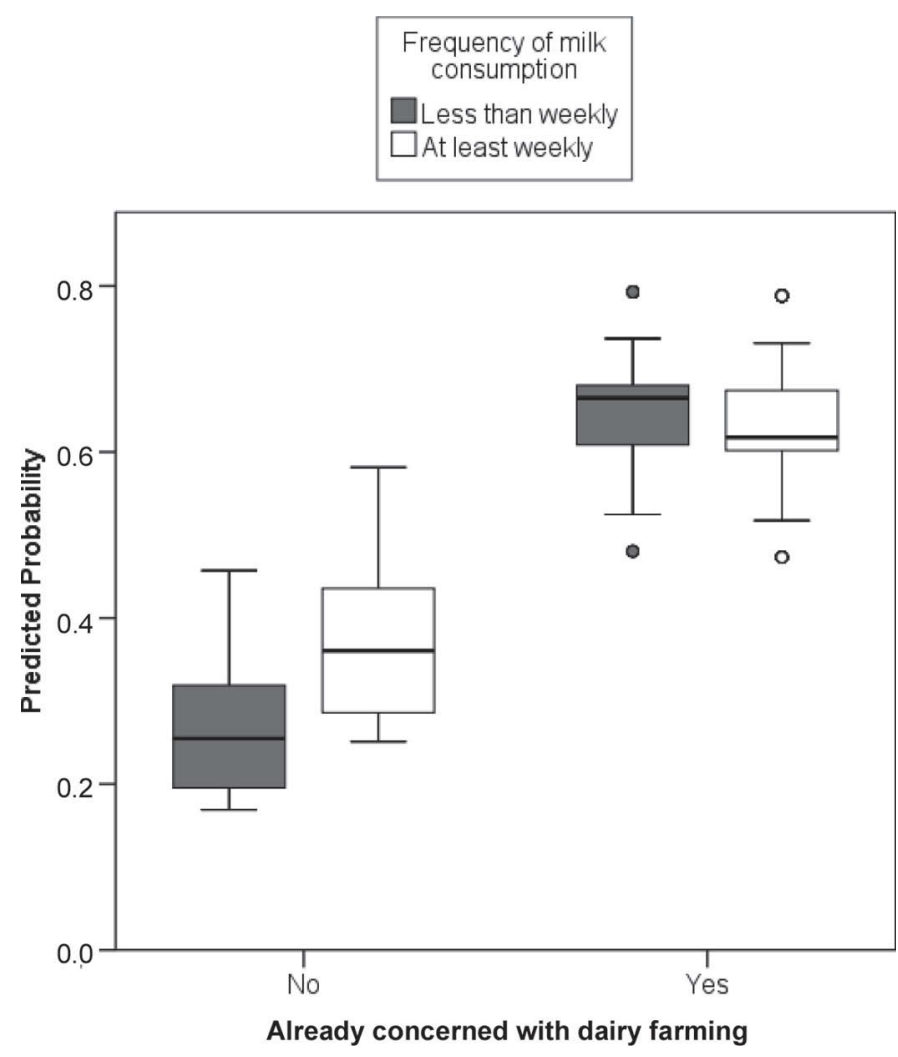

Figure 1. Predicted probability of knowing that milk contains hormones without prior hormone treatment compared with not knowing $(\mathrm{n}=1,569)$. Box $=$ interquartile range $(\mathrm{IQR}, 25$ th to 75 th percentile of values); dark line within box $=50$ th percentile (median); whiskers $=$ data range, not exceeding 25 th percentile $-1.5 *$ IQR and 75 th quartile + $1.5 *$ IQR; dot $=$ outlier. findings are clearly limited to consumers in Germany. Therefore, further research is warranted to generate similar data for other countries and societies with comparable dairy industries.

\section{CONCLUSIONS}

Consumers in Germany lacked basic knowledge about milk production but generally perceived assisted reproductive technologies in dairy cows negatively. Education is necessary to inform consumers about food production and modern farm management practices.

\section{ACKNOWLEDGMENTS}

We would like to thank the Institute for Demoscopy Allensbach (Allensbach, Germany) for their support conducting this study.

\section{REFERENCES}

Boogaard, B. K., B. B. Bock, S. J. Oosting, J. S. C. Wiskerke, and A. J. van der Zijpp. 2011. Social acceptance of dairy farming: The ambivalence between the two faces of modernity. J. Agric. Environ. Ethics 24:259-282.

Bruhn, C. M., A. Cotter, K. Diaz-Knauf, J. Sutherlin, E. West, N. Wightman, E. Williamson, and M. Yaffee. 1992. Consumer attitudes and market potential for dairy products utilizing fat substitutes. J. Dairy Sci. 75:2569-2577.

Curtis, S. E. 1987. Public mood and how we respond. J. Dairy Sci. 70:2708-2710.

Foote, R. H. 2002. The history of artificial insemination: Selected notes and notables. J. Anim. Sci. 80(E. Suppl.):E22-E32.

Fricke, P. M., J. O. Giordano, A. Valenza, G. Lopes Jr., M. C. Amundson, and P. D. Carvalho. 2014. Reproductive performance of lactating dairy cows managed for first service using timed artificial insemination with or without detection of estrus using an activitymonitoring system. J. Dairy Sci. 97:2771-2781. 
Gaskell, G., N. Allum, M. Bauer, J. Durant, A. Allansdottir, H. Bonfadelli, H. Boy, S. de Cheveigné, B. Fjaestad, J. M. Gutteling, J. Hampel, E. Jelsøe, J. Correia Jesuino, M. Kohring, N. Kronberger, C. Midden, T. H. Neilsen, A. Przestalski, T. Rusanen, G. Sakellaris, H. Torgersen, T. Twardowski, and W. Wagner. 2000. Biotechnology and the European public. Nat. Biotechnol. 18:935-938.

Hallman, W. K., W. C. Hebden, H. L. Aquino, C. L. Cuite, and J. T. Lang. 2003. Public Perceptions of Genetically Modified Foods: A National Study of American Knowledge and Opinion. (Publication number RR-1003-004). Food Policy Institute, Cook College, Rutgers-The State University of New Jersey, New Brunswick, NJ.

Higgins, H. M., E. Ferguson, R. F. Smith, and M. J. Green. 2013. Using hormones to manage dairy cow fertility: the clinical and ethical beliefs of veterinary practitioners. PLoS ONE 8:e62993.

Institute for Demoscopy Allensbach. 2002. Image der Landwirte und der Landwirtschaft in Deutschland- Eine Umfrage des Instituts für Demoskopie Allensbach für die DLG. Archive number 7033. October/November 2002. Institute for Demoscopy Allensbach, Allensbach, Germany.

Jung, M. E., C. Mistry, J. E. Bourne, M.-J. Perrier, K. A. Martin Ginis, and A. E. Latimer-Cheung. 2015. A qualitative investigation of adults' perceived benefits, barriers and strategies for consuming milk and milk products. Health Educ. J. 74:364-378.

Lassen, J., M. Gjeris, and P. Sandøe. 2006. After Dolly: Ethical limits to the use of biotechnology on farm animals. Theriogenology 65:992-1004

Lucy, M. C. 2001. Reproductive loss in high-producing dairy cattle: Where will it end? J. Dairy Sci. 84:1277-1293.

Moore, K., and W. W. Thatcher. 2006. Major advances associated with reproduction in dairy cattle. J. Dairy Sci. 89:1254-1266.

Pursley, J. R., M. O. Mee, and M. C. Wiltbank. 1995. Synchronization of ovulation in dairy cows using $\mathrm{PGF}_{2 \alpha}$. Theriogenology 44:915-923.

Rabiee, A. R., I. J. Lean, and M. A. Stevenson. 2005. Efficacy of Ovsynch program on reproductive performance in dairy cattle: A meta-analysis. J. Dairy Sci. 88:2754-2770.

Refsdal, A. O. 2000. To treat or not to treat: A proper use of hormones and antibiotics. Anim. Reprod. Sci. 60-61:109-119.

Rozin, P., C. Fischler, S. Imada, A. Sarubin, and A. Wrzesniewski. 1999. Attitude to food and the role of food in life in the USA Japan, Flemish Belgium and France: Possible implications for the diet-health debate. Appetite 33:163-180.

Schaack, D., C. Rampold, and H.-C. Behr. 2014. Agrarmarkt Informations-Gesellschaft mbH (AMI) Markt Studie: Strukturdaten im ökologischen Landbau in Deutschland 2013-Bodennutzung, Tierhaltung und Verkaufserlöse. Accessed July 9, 2015. https:// www.ami-informiert.de/fileadmin/redaktion/bio_daten/ strukturdaten/Strukturdaten_und_Verkaufserloese_2013_PDF. pdf.
Schröck, R. 2014. The demand for organic food in Germany: Econometric analyses of demand structure, price formation and product labelling. Doctoral Dissertation. Justus-LiebigUniversität Gießen, Germany. [in German with English abstract http://geb.uni-giessen.de/geb/volltexte/2014/10920/pdf/ SchroeckRebecca_2014_05_14.pdf.

Statistisches Bundesamt. 2011. Microcensus. Accessed Jan. 25, 2016. https://www.destatis.de/EN/Meta/abisz/Mikrozensus_e.html.

Statistisches Bundesamt. 2013. Land- und Forstwirtschaft, FischereiViehhaltung der Betriebe Agrarstrukturerhebung. https://www. destatis.de/DE/Publikationen/Thematisch/LandForstwirtschaft/ ViehbestandTierischeErzeugung/Viehhaltung2030213139004. pdf?__blob=publicationFile.

Stopponi, M. A., G. L. Alexander, J. B. McClure, N. M. Carroll, G. W. Divine, J. H. Calvi, S. J. Rolnick, V. J. Strecher, C. C. Johnson, and D. P. Ritzwoller. 2009. Recruitment to a randomized web-based nutritional intervention trial: Characteristics of participants compared to non-participants. J. Med. Internet Res. 11:e38. http://dx.doi.org/10.2196/jmir.1086.

Tenhagen, B.-A., M. Drillich, R. Surholt, and W. Heuwieser. 2004. Comparison of timed AI after synchronized ovulation to AI at estrus: Reproductive and economic considerations. J. Dairy Sci. 87:85-94.

USDA. 2009. Dairy 2007, Part IV: Reference of dairy cattle health and management practices in the United States, 2007. \#N494.0209. USDA-APHIS-VS, CEAH. Fort Collins, CO. Accessed July 10 2015. http://www.aphis.usda.gov/animal_health/nahms/dairy/ downloads/dairy07/Dairy07_dr_PartIV.pdf.

Verbeke, W., and J. Viaene. 1999. Beliefs, attitude and behavior towards fresh meat consumption in Belgium: Empirical evidence from a consumer survey. Food Qual. Prefer. 10:437-445.

von Keyserlingk, M. A. G., and W. Heuwieser. 2008. Welfare and behavior of dairy cows and their relation to uterine health. Proc. 3rd Mtg. Dairy Cattle Reproductive Council (DCRC), Omaha, NE. DCRC, Heartland, WI.

von Keyserlingk, M. A. G., N. P. Martin, E. Kebreab, K. F. Knowlton, R. J. Grant, M. Stephenson, C. J. Sniffen, J. P. Harner III, A D. Wright, and S. I. Smith. 2013. Sustainability of the US dairy industry. J. Dairy Sci. 96:5405-5425.

Weatherell, C., A. Tregear, and J. Allinson. 2003. In search of the concerned consumer: UK public perceptions of food, farming and buying local. J. Rural Stud. 19:233-244

Worsley, A., W. C. Wang, S. Byrne, and H. Yeatman. 2013. Patterns of food safety knowledge among Australians: A latent class approach. J. Food Prot. 76:646-652. http://dx.doi.org/10.4315/0362-028X. JFP-12-449. 


\section{APPENDIX}

Table A1. Questionnaire administered to a panel of 1,646 Germans

Question (instruction for or action by interviewer)

How often do you drink milk, no matter whether a cup of milk or chocolate, or you eat something with milk such as cereal? Would you say...

(In case of queries: "When you drink milk only with coffee, that is not what we mean here")

(Interviewer gives green list)

In general: what do you find important in milk? Please tell me according to this list.

(circle all that apply)

A cow can only give milk when she already gave birth to a calf. Have you heard about that or have you not heard about that but you would have expected it or would you have not necessarily thought that?

There are different possibilities how a cow can get pregnant; for example, by using artificial insemination or naturally with a bull. What do you think: Does the way the cow gets pregnant influence the quality of the milk that she will give later or is there no influence?

(Interviewer hands over blue card game and white picture page)

On these cards are different possibilities describing how a cow can get pregnant. What do you think: With which possibilities is the milk that the cow gives later better or rather worse? (Circle the respective) (interviewee sorts the cards according to milk quality being better or worse)

(Interviewer hands over blue list)

Besides natural breeding by a bull, there are other possibilities or procedures for how a cow can get pregnant. Independent of your opinion whether it influences milk quality or not: Are there procedures on this list that you disapprove of and that, in your opinion, should not be used for getting a cow pregnant? (circle all that apply)

The milk that comes from healthy cows that did not receive hormone treatment also contains hormones. Did you know that or did you not know that?

Have you ever concerned yourself with dairy farming; for example, how dairy cows are housed, how milk is produced etc. or is this not the case?
Answer categories

Multiple times daily

Daily

Multiple times per week

Once a week

Less often

Never*

No answer*

${ }^{*}$ Go to question 3

The taste

An environmentally friendly packaging

The brand

Fat content

Where the milk comes from

That it is cheap

That the milk was produced sustainably

That the cows were kept according to good animal welfare

That it is an organic product

That it is fresh milk and not UHT milk

That the milk comes from a small farm

None of these

No answer

I have heard that

I would have thought so

I would have not thought so

Undecided; no answer

There is an influence

There is no influence*

Don't know; no answer*

* Go to question 5

Natural fertilization by a bull

Artificial insemination without hormone treatment of the cow

Artificial insemination after a hormone treatment of the cow Transfer of an embryo (i.e., fertilized egg that was produced by fertilization in the Petri dish)

Yes, specifically:

Special artificial insemination with prior selection of semen cells so that only female calves are born

Regular artificial insemination

Transfer of an embryo, so a fertilized egg, that was produced by fertilization in the Petri dish

Transfer of an embryo that was produced by cloning

Hormone treatment of a cow to increase her fertility

No, I do not disapprove of any of these

No answer

I knew that

I did not know that

No answer

Already concerned myself with dairy farming

Not the case

No answer 